\title{
EDITORIAL
}

\section{Osteoporosis during COVID-19 Pandemic}

\author{
LAM $\mathrm{RH}^{1}$, JAYA KUMAR $\mathrm{M}^{2}$, ISA NAINA $\mathrm{M}^{3}$, MAJMIN $\mathrm{SH}^{1}$, \\ RASHIDI MPM ${ }^{1}$
}

${ }^{1}$ Department of Family Medicine, ${ }^{2}$ Department of Physiology, ${ }^{3}$ Department of Pharmacology, Faculty of Medicine, Universiti Kebangsaan Malaysia Medical Centre,

Jalan Yaacob Latif, Bandar Tun Razak, 56000 Cheras, Kuala Lumpur, Malaysia.

Osteoporosis is a skeletal condition characterised by decreased bone mass and weak bone strength, leading to bone fragility and fracture susceptibility (NIH Consensus Development Panel on Osteoporosis Prevention 2001). Osteoporosis and fragility fractures are major health conditions and remains an important cause of mortality and morbidity around the world, particularly among the elderly. Worldwide, an estimated 200 million women are affected by osteoporosis (Kanis et al. 2012). The Asian population has a higher overall prevalence than western countries, owing to the fact that they have a lower body mass index and shorter height (Babbar et al. 2006). In Malaysia, the prevalence of osteoporosis among women was reported to be $24.1 \%$ in 2005, with hips being most affected (Lim et al. 2005).

COVID-19, which first appeared in late 2019 in Wuhan, China, causing clusters of severe respiratory illness, has subsequently spread swiftly throughout the world, and Malaysia is not spared, with climbing case numbers and mortalities. COVID-19 has infected people of all ages, ethnicities and genders while spreading at an alarming rate throughout communities. COVID-19 infections range from simple colds to more serious illnesses like pneumonia, bronchitis, severe acute respiratory distress syndrome (ARDS), multi-organ failure and death (Sanyaolu et al. 2020). As of July 2021, the global cumulative number of cases is almost 194 million with over 4 million deaths from COVID-19 (World Health Organization 2021). As for Malaysia, we have seen almost 1.7 million cases in a country of 32 million people with more than 15,000 deaths (Ministry of Health Malaysia 2021).

It is generally recognised that the COVID-19 pandemic has significantly disrupted worldwide healthcare delivery. Since the first recorded cases of the disease, many nations have taken extraordinary steps to limit the virus's spread, including travel bans, widespread social isolation, gathering restrictions, and national 
lockdowns. As part of public health measures, infection control strategies such as regular hand sanitisation, washing, social distancing and in recent months, vaccinations have been utilised. While these measures have been partly effective in containing viral transmission, they have resulted in significant disruption of healthcare and social services. Understandably, these restrictions posed difficulties in managing a variety of chronic medical problems (Yu et al. 2020). Much of healthcare resources and attention have been directed towards urgent care of COVID-19 as the country deals with one of the worst health crises to date. Prioritisation of urgent care over elective care poses challenges in treating a range of chronic conditions, including osteoporosis. The potential impact of this shift of focus is significant, given that osteoporosis is the most prevalent bone disease worldwide, affecting one in every three women and one in every five men at some point in their lives (Johnell \& Kanis 2005). Healthcare expenses and long-term morbidity associated with osteoporosis are projected to rise in the coming years as the elderly population grows. Osteoporotic fractures are expected to result in the loss of 5.8 million productive years due to disability and decreased relative survival (Hampson et al. 2021).

Osteoporosis does not take a break during the COVID-19 pandemic. Lockdowns had a substantial influence on physical activity levels during the pandemic. An Italian study found a decrease of 2.3 hours of sports activity weekly during the COVID-19 lockdown (Pietrobelli et al. 2020), while a survey of 1,047 participants from Asia, Africa, and Europe found a $33.5 \%$ decrease in physical activity duration, $42.7 \%$ decrease in exercise intensity and a 5 to 8-hour increase in sitting time (Ammar et al. 2020). These findings showed the potential negative impact of quarantines and self-isolation on physical activity and sedentary behaviour. As a consequence, prolonged home isolation due to the pandemic increases the risk of muscle loss and vitamin D deficiency, which in turn increases the fall risk and consequent osteoporotic fractures (Falchetti et al. 2021). Additionally, hospitalisation for COVID-19 results in prolonged bed rest, with an average hospital stay of 11 days (Zhou et al. 2020). Severe COVID-19 infection results in admission to intensive care units (ICU), further restricting mobility, with a median ICU stay of 8 days (Zhou et al. 2020). Even a short duration of reduced activity can lead to muscle loss of $1.7 \%$ within 2 days and $5.5 \%$ after only 7 days (Kilroe et al. 2019). This is particularly pertinent given the increased hospitalisation rates of older adults.

Social isolation during the COVID-19 pandemic has been shown to increase stress and anxiety levels (Lei et al. 2020), which can result in atrophic gene expression and muscular atrophy (Allen et al. 2010). Psychological stress has been shown to influence dietary choices, with increased consumption of sweet, fatty foods that are low in protein, leading to increased muscle loss (Gibson 2006). As social interactions are important in 
encouraging people to exercise, the lack of it during quarantine could lead to a significant reduction in physical activity among older adults (Fingerman et al. 2020). Loneliness could hasten physical and cognitive deterioration in older adults, putting them at an increased risk of falling (Zhong et al. 2017).

Vitamin D, especially in the active form of 1,25-dihydroxycholecalciferol, is known to be linked to bone health. Several studies have demonstrated an association between low vitamin D status and decreased muscle mass (Luo et al. 2018) and a variety of chronic illnesses (Wang et al. 2017). With a half-life of 13 to 15 days for vitamin D (Jones et al. 2014) and lower levels of outdoor activity during the COVID-19 pandemic (Ammar et al. 2020), spending more time indoors leads to less direct sunlight exposure, which has a negative impact on vitamin $D$ production (Van Schoor \& Lips 2017). Reduction of muscle mass and loss of function associated with sarcopenia contribute to the development of frailty (Landi et al. 2015), consequently increasing the risk of falls (Gadelha et al. 2018).

Three meta-analyses have demonstrated that calcium in combination with vitamin $\mathrm{D}$ is effective at reducing fracture risk. Vitamin D in combination with calcium resulted in a $16-33 \%$ reduction in the risk of hip fracture and a 5-19\% reduction in the risk of any fracture, as compared to a placebo or control group (Avenell et al. 2014; Tricco et al. 2017; Wu \& Pang 2017). Vitamin D supplementation reduced the incidence of falls by $28 \%$ among people residing in care homes (Cameron et al. 2018). In addition to its role in bone health maintenance, interest in the benefits of Vitamin $\mathrm{D}$ on the immune system has been increasing as of late. Vitamin D may exert a moderating influence on inflammatory responses via its effects on both innate and adaptive immunity (Mora et al. 2008). Apart from improvement in balance (Pfeifer et al. 2009), muscle strength and function (Beaudart et al. 2014; Janssen et al. 2002), vitamin D supplementation has been shown to reduce risk of acute respiratory infection by $12 \%$ (Martineau et al. 2017). Critically ill patients commonly have a vitamin D deficiency (Perron \& Lee 2013), which in turn is associated with a higher rates of ICU admission, severe illness, ARDS and increased ICU mortality (Perron \& Lee 2013; Remmelts et al. 2012). A recent meta-analysis found a link between vitamin D insufficiency and the severity of COVID-19 infection, with the former being associated with higher hospitalisation and death (Pereira et al. 2020). Despite the sunny tropical climate, low vitamin D levels are not uncommon in Malaysia; $71 \%$ of Malay post-menopausal women (Rahman et al. 2004) and $67 \%$ of teachers had vitamin D deficiencies in Malaysia (Shafinaz \& Moy 2016).

Lifestyle measures are an essential component in the prevention and management of osteoporosis. Eating a healthy balanced diet, limiting alcohol intake and quitting smoking are all important steps in addition to a regular exercise regimen. Maintaining an adequate dietary consumption 
of calcium and vitamin D $(1000 \mathrm{mg}$ and 800 UI, respectively) is highly advisable (Conley et al. 2020; Ministry of Health Malaysia 2015). An adequate and sensible exposure to the sun is also essential for obtaining the required Vitamin D. For example, 5 to 15 minutes of exposed arms and legs between the times of 10 am to 3 $\mathrm{pm}$ is recommended (Holick 2005). Moreover, resistance exercise has been found to improve muscle size, strength (Stewart et al. 2014), and bone mineral density (Hong \& Kim 2018) on top of improvement in LDL cholesterol and blood pressure (Nascimento et al. 2018; Kim \& Kim 2013), glycaemic control (Egger et al. 2013), functional capacity (Liao et al. 2020; Yoon et al. 2019), sleep (Yoon et al. 2019) as well as cognitive performance (Macaulay et al. 2020).

Therearemany methodsfor assessing fracture risk but the commonest is the Fracture Risk Assessment Tool (FRAX), which is accessible in 66 countries and covers about three-quarters of the world's population. This tool has been incorporated in a number of national guidelines on osteoporosis, including Malaysia, in order to initiate relevant therapies that may lead to a reduction of fractures (Kanis et al. 2016). During the pandemic, the FRAX tool usage was significantly reduced by $23 \%$ and $58 \%$ in March and April 2020, respectively (McCloskey et al. 2021). In Europe, many countries have decreased their use by at least $50 \%$. Similar incidence were also seen in Latin America, but less pronounced in Asian nations.

Bone mineral density (BMD) measurement by dual-energy $\mathrm{X}$-ray absorptiometry (DEXA) is invaluable in osteoporosis diagnosis and can improve the accuracy of fracture risk assessment when used in tandem with tools like FRAX. Randomised controlled trials of people with low BMD scores and/or vertebral fragility fractures supported the use of osteoporosis therapies to decrease fracture risk. Following therapy, an increase in BMD was associated with a decrease in fracture risk (Camacho et al. 2020). Measurements of BMD, which are typically done in secondary and tertiary-care facilities, have been disrupted during the pandemic. The number of DEXA measurements has decreased as a consequence of social distancing and strict infection control strategies (Fuggle et al. 2021). The frail and elderly, who are especially prone to osteoporotic fractures, have been hesitant to visit a hospital due to worries of contracting COVID-19.

In order to address the delays in obtaining DEXA imaging, FRAX score has been proposed as a tool to risk stratify patients into low, intermediate and high risk via telephone consultation in which the patient's height, weight, gender, age and clinical risk factors are used. Low-risk patients may be reassured following the FRAX score calculation and have their DEXA scan deferred. At the same time, intermediate-risk patients can proceed with DEXA measurements while highrisk patients can be treated without requiring a DEXA (Sapkota et al. 2021). This is in line with recommendation in the Malaysian osteoporosis guideline where high-risk individuals (10-year fracture risk of $>20 \%$ or hip fracture 
risk of $>3 \%$ ) may be treated when DEXA scans are unavailable (Ministry of Health Malaysia 2015). The screening in the community to reduce fractures in older women (SCOOP) study established the efficacy of nonDEXA-based fracture prevention in individuals at high risk of fracture. Over a five-year period, treatment based on the FRAX score resulted a decreased hip fractures by $28 \%$ compared to the control group (Shepstone et al. 2018).

There are conflicting results on rates of hip fracture during the pandemic, with some reporting no change compared to previous years (Ogliari et al. 2020), while others mentioning changes of various degrees, be it positive or negative (Arafa et al. 2020; Malik-Tabassum et al. 2020; Maniscalco et al. 2020). Surgical treatment of osteoporotic fractures has been delayed due to surgical wards being repurposed to cope with increasing COVID-19 admissions (Arafa et al. 2020). A UK study has found an $80 \%$ reduction in orthogeriatric review due to redeployment and a $30 \%$ reduction in calcium and vitamin prescriptions was observed during the pandemic (Stephens et al. 2020). Concurrent COVID-19 infection increased the risk of mortality by $36 \%$ following hip fracture, as compared to a mortality of $2 \%$ in those without COVID-19 (Lim \& Pranata 2021). This is of great importance especially among the elderly, as they are at a higher risk of getting COVID-19 or suffering an osteoporotic fracture. Additionally, the 30-day mortality rate for fracture patients doubled during the pandemic when compared to pre-pandemic levels, from $4 \%$ to $9 \%$ in the former (Lim et al. 2021). Post-discharge rehabilitation services were affected as a result of stringent infection control measures and social distancing as well.

The pandemic has further exacerbated the treament gap seen prior to the pandemic (Giangregorio et al. 2006), as osteoporosis was considered low priority as compared to acute care of COVID-19 patients. A number of osteoporotic treatments required attendance at a healthcare facility for infusion or injection. During the pandemic, the capacity of healthcare facilities to deliver infusion treatments has been reduced (Fuggle et al. 2021). Numerous patients refused or were unable to attend scheduled treatments due to fear of getting COVID-19 and restrictions on movement imposed by the lockdown. As zoledronic acid has a prolonged skeletal retention duration, the timing of subsequent infusions is less crucial because the anti-resorptive action is maintained for about two years following administration. Therefore, zoledronic acid and other bisphosphonates have demonstrated a prolonged protective effect against fractures after treatment (Grey et al. 2012; Grey et al. 2020; Schwartz et al. 2010; Watts et al. 2008). This is in contrast to denosumab, which has a unique disadvantage in that its inhibitory effect on bone resorption rapidly diminishes after a dose delay of more than 7 months (Bone et al. 2011; Cummings et al. 2018). Further complicating this, discontinuation of denosumab results in a rapid increase in bone remodelling lasting 6 months 
to a year, which is associated with the development of vertebral fractures and hypercalcemia (Tsourdi et al. 2017). Unlike denosumab, teriparatide cessation results in loss of bone mass over the first 12 months but does not result in a rapid increase in bone remodelling or vertebral fractures (Leder et al. 2009). Bone loss after cessation of teriparatide can be mitigated by oral bisphosphonates, which have been demonstrated to preserve BMD increases and reduce fractures for up to 5 years (Oswald et al. 2019). Patients who were on teriparatide should be transitioned to oral bisphosphonate if delays exceed 2-3 months (Yu et al. 2020). Similarly, physicians should consider temporarily prescribing an oral bisphosphonate for patients who are expected to have delayed denosumab injection beyond 7 months, in order to maintain bone mineral density and reduce the risk of fracture (Yu et al. 2020). In patients with known upper gastrointestinal disorders, ibandronate and risedronate are preferred as they have been reported to have fewer gastrointestinal side effects (Marshall 2002). It is recognised that intravenous bisphosphonate therapy may result in an acute phase response in up to $50 \%$ of individuals (Popp et al. 2017), especially in treatmentnaive patients. Symptoms of the acute phase response, which include fever and myalgia, may be mistaken for a COVID-19 infection. Experts advise against testing for COVID-19 unless symptoms last longer than four days (Hampson et al. 2021). As COVID-19 infection can lead to thrombosis (Xiong et al. 2021), oestrogen and selective oestrogen receptor modulators such as raloxifene should be used with caution since they slightly increase thrombotic risks (Adomaityte et al. 2008).

Bone resorption and bone loss might result from increased pro-inflammatory cytokine production and prolonged immobilisation in ill COVID-19 patients (Huang et al. 2020). The infection's medium- and long-term consequences may have a detrimental effect on the skeletal system. Patients with severe COVID-19 infection continue to have health issues, which include dyspnoea, cardiovascular problems, muscle loss and weakness, mobility issues as well as loss of independence (Huang et al. 2021). Comprehensive rehabilitation treatment plan is needed for this group of people and when appropriate, fracture risk assessment should be carried out with a view to start osteoporosis treatment (Napoli et al. 2020).

Telemedicine has gained traction during the COVID-19 pandemic. It has come a long way from phone consultation decades ago. In addition to being able to assess for risk factors for fractures and falls, telemedicine enables virtual examination of patients by healthcare providers. Despite its limitations, virtual examination of the musculoskeletal system has been developed and was considered to be promising by certain clinics, especially during the COVID-19 pandemic (Laskowski et al. 2020; Tanaka et al. 2020). Telemedicine not only enables healthcare practitioners to see their patients and their degree of participation, particularly during discussions about osteoporosis therapy, 
it also allows for the use of visual image aids to help patients comprehend and participate in their treatment (Narla \& Adler 2021). A Canadian study showed the viability of virtually delivering osteoporosis therapy via telemedicine, noting that patients' perceptions of care via telemedicine were equivalent to those of face-to-face appointments, with the additional advantages of convenience, decreased travel time and cost savings (Palcu et al. 2020). When physiotherapy and occupational therapy are required, telemedicine enables therapists to advise on safety and exercises after visualising and assessing patients' home environments. Telemedicine-based physical therapy was found to be well received by patients during the pandemic (Tenforde et al. 2020). Telemedicine also allows primary care providers to consult with experts in osteoporosis who would be able to offer real-time feedback which can prove educational as well as identify and prioritise more difficult patients for treatment by a subspecialty clinic. A study in Northern Ireland found e-consultation to be beneficial in improving patient access to osteoporosis service (Lindsay et al. 2020). Osteoporosis care can be further improved by the sharing of challenging cases, use of mutually accessible records and seamless referral of stabilised patients back to primary care in order to distribute care burden. Continuity of care is critical for treatment success. With reduced access to clinical services and longer wait times during the COVID-19 pandemic, telemedicine can be a costeffective solution.
As osteoporosis is a silent disease until complications arise from fragility fractures, the onus is on healthcare providers to diagnose early and manage appropriately. However, studies have found a low rate of diagnosis and treatment of osteoporosis (Chami et al. 2006; Choi et al. 2012; Giangregorio et al. 2006). This dismal rate will almost certainly decline to undetectable levels throughout the pandemic (Napoli et al. 2020). Therefore, there is a need to encourage physicians, especially those in primary care to continue screening for osteoporosis and addressing fall risk in patients during the pandemic.

In conclusion, osteoporosis should not be neglected during the COVID-19 pandemic. Attention should be given to the care of individuals who have osteoporosis in order to prevent a spike in osteoporotic fractures and a surge in non-communicable diseases in the coming years. Physicians should be encouraged to continue screening for those at risk during clinical encounters. Particular attention should be paid to the preventive part of osteoporosis, in terms of physical activity at home during the pandemic and adequate calcium and vitamin D intake with supplementation if necessary. Moving forward, appropriate changes in the way healthcare is delivered, for example telemedicine, may be useful during this pandemic.

\section{REFERENCES}

Adomaityte, J., Farooq, M., Qayyum, R. 2008. Effect of raloxifene therapy on venous thromboembolism in postmenopausal women. A meta-analysis. Thromb Haemost 99(2): 33842. 
Allen, D.L., McCall, G.E., Loh, A.S., Madden, M.C., Mehan, R.S. 2010. Acute daily psychological stress causes increased atrophic gene expression and myostatin-dependent muscle atrophy. Am J Physiol Regul Integr Comp Physiol 299(3): R889-R898.

Ammar, A., Brach, M., Trabelsi, K., Chtourou, H., Boukhris, O., Masmoudi, L., Bouaziz, B., Bentlage, E., How, D., Ahmed, M., Müller, P., Müller, N., Aloui, A., Hammouda, O., PaineirasDomingos, L.L., Braakman-Jansen, A., Wrede, C., Bastoni, S., Pernambuco, C.S., Mataruna, L., Taheri, M., Irandoust, K., Khacharem, A. Bragazzi, N.L., Chamari, K., Glenn, J.M., Bott, N.T., Gargouri, F., Chaari, L., Batatia, H., Ali, G.M., Abdelkarim, O., Jarraya, M., Abed, K.E., Souissi, N., Van Gemert-Pijnen, L., Riemann, B.L., Riemann, L., Moalla, W., Gómez-Raja, J., Epstein, M., Sanderman, R., Schulz, S.V., Jerg, A., Al-Horani, R., Mansi, T., Jmail, M., Barbosa, F., Ferreira-Santos, F., Šimuni, B., Pišot, R. Gaggioli, A., Bailey, S.J., Steinacker, J.M., Driss, T., Hoekelmann, A. 2020. Effects of COVID-19 Home Confinement on Eating Behaviour and Physical Activity: Results of the ECLB-COVID19 International Online Survey. Nutrients 12(6): 1583.

Arafa, M., Nesar, S., Abu-Jabeh, H., Jayme, M.O.R., Kalairajah, Y. 2020. COVID-19 pandemic and hip fractures: impact and lessons learned. Bone Jt Open 1(9): 530-40.

Avenell, A., Mak, J.C., O'Connell, D. 2014. Vitamin $\mathrm{D}$ and vitamin $\mathrm{D}$ analogues for preventing fractures in post-menopausal women and older men. Cochrane Database Syst Rev 2014(4): Cd000227.

Babbar, R.K., Handa, A.B., Lo, C.M., Guttmacher, S.J., Shindledecker, R., Chung, W., Fong, C., Ho-Asjoe, H., Chan-Ting, R., Dixon, L.B. 2006. Bone health of immigrant Chinese women living in New York City. J Community Health 31(1): 7-23.

Beaudart, C., Buckinx, F., Rabenda, V., Gillain, S., Cavalier, E., Slomian, J., Petermans, J., Reginster, J.Y., Bruyère, O. 2014. The effects of vitamin D on skeletal muscle strength, muscle mass, and muscle power: a systematic review and metaanalysis of randomized controlled trials. J Clin Endocrinol Metab 99(11): 4336-45.

Bone, H.G., Bolognese, M.A., Yuen, C.K., Kendler, D.L., Miller, P.D., Yang, Y.C., Grazette, L., San Martin, J., Gallagher, J.C. 2011. Effects of denosumab treatment and discontinuation on bone mineral density and bone turnover markers in postmenopausal women with low bone mass. J Clin Endocrinol Metab 96(4): 97280.

Camacho, P.M., Petak, S.M., Binkley, N., Diab, D.L., Eldeiry, L.S., Farooki, A., Harris, S.T.,
Hurley, D.L., Kelly, J., Lewiecki, E.M. PessahPollack, R., McClung, M., Wimalawansa, S.J., Watts NB. 2020. American Association of Clinical Endocrinologists/American College of Endocrinology clinical practice guidelines for the diagnosis and treatment of postmenopausal osteoporosis-2020 update. Endocr Pract 26(suppl 1): 1-46.

Cameron, I.D., Dyer, S.M., Panagoda, C.E., Murray, G.R., Hill, K.D., Cumming, R.G., Kerse, N. 2018. Interventions for preventing falls in older people in care facilities and hospitals. Cochrane Database Syst Rev 9(9): CD005462

Chami, G., Jeys, L., Freudmann, M., Connor, L., Siddiqi, M. 2006. Are osteoporotic fractures being adequately investigated? A questionnaire of GP \& orthopaedic surgeons. BMC Fam Pract 7: 7.

Choi, Y.J., Oh, H.J., Kim, D.J., Lee, Y., Chung, Y. S. 2012. The prevalence of osteoporosis in Korean adults aged 50 years or older and the higher diagnosis rates in women who were beneficiaries of a national screening program: the Korea National Health and Nutrition Examination Survey 2008-2009. J Bone Miner Res 27(9): 1879-86.

Conley, R.B., Adib, G., Adler, R.A., Åkesson, K. E., Alexander, I.M., Amenta, K.C., Blank, R.D., Brox, W.T., Carmody, E.E., ChapmanNovakofski, K., Clarke, B.L., Cody, K.M., Cooper, C., Crandall, C.J., Dirschl, D.R., Eagen, T.J., Elderkin, A.L., Fujita, M., Greenspan, S. L., Halbout, P., Hochberg, M.C., Javaid, M., Jeray, K.J., Kearns, A.E., King, T., Koinis, T.F., Koontz, J.S., Kužma, M., Lindsey, C., Lorentzon, M., Lyritis, G.P., Michaud, L.B., Miciano, A., Morin, S.N., Mujahid, N., Napoli, N., Olenginski, T. P., Puzas, J.E., Rizou, S., Rosen, C.J., Saag, K., Thompson, E., Tosi, L.L., Tracer, H., Khosla, S., Kiel, D.P. 2020. Secondary fracture prevention: consensus clinical recommendations from a multistakeholder coalition. J Bone Miner Res 35(1): 36-52.

Cummings, S.R., Ferrari, S., Eastell, R., Gilchrist, N., Jensen, J.E.B., McClung, M., Roux, C., Törring, O., Valter, I., Wang, A.T. Brown J.P. 2018. Vertebral fractures after discontinuation of denosumab: a post hoc analysis of the randomized placebo-controlled FREEDOM trial and its extension. J Bone Miner Res 33(2): 1908.

Egger, A., Niederseer, D., Diem, G., Finkenzeller, T., Ledl-Kurkowski, E., Forstner, R., Pirich, C., Patsch, W., Weitgasser, R., Niebauer, J. 2013. Different types of resistance training in type 2 diabetes mellitus: effects on glycaemic control, muscle mass and strength. Eur J Prev Cardiol 20(6): 1051-60

Falchetti, A., Mohseni, M., Tramontana, F., Napoli, N. 
2021. Secondary prevention of fragility fractures: where do we stand during the COVID-19 pandemic? J Endocrinol Invest 44(11): 2521-4.

Fingerman, K.L., Huo, M., Charles, S.T., Umberson, D.J. 2020. Variety Is the Spice of Late Life: Social Integration and Daily Activity. J Gerontol B Psychol Sci Soc Sci 75(2): 377-88.

Fuggle, N.R., Singer, A., Gill, C., Patel, A., Medeiros, A., Mlotek, A.S., Pierroz, D.D., Halbout, P., Harvey, N.C., Reginster, J.Y., Cooper, C., Greenspan, S.L. 2021. How has COVID-19 affected the treatment of osteoporosis? An IOFNOF-ESCEO global survey. Osteoporos Int 32(4): 611-7.

Gadelha, A.B., Neri, S.G.R., Oliveira, R.J., Bottaro, M., David, A.C., Vainshelboim, B., Lima, R.M. 2018. Severity of sarcopenia is associated with postural balance and risk of falls in communitydwelling older women. Exp Aging Res 44(3): 258-69.

Giangregorio, L., Papaioannou, A., Cranney, A., Zytaruk, N., Adachi, J.D. 2006. Fragility fractures and the osteoporosis care gap: an international phenomenon. Semin Arthritis Rheum 35(5): 293-305.

Gibson, E.L. 2006. Emotional influences on food choice: sensory, physiological and psychological pathways. Physiol Behav 89(1): 53-61.

Grey, A., Bolland, M.J., Horne, A., Wattie, D., House, M., Gamble, G., Reid, I.R. 2012. Five years of anti-resorptive activity after a single dose of zoledronate-results from a randomized doubleblind placebo-controlled trial. Bone 50(6): 1389-93.

Grey, A., Horne, A., Gamble, G., Mihov, B., Reid, I. R., Bolland, M. 2020. Ten years of very infrequent zoledronate therapy in older women: an openlabel extension of a randomized trial. J Clin Endocrinol Metab 105(4): 1641-7.

Hampson, G., Stone, M., Lindsay, J.R., Crowley, R.K., Ralston, S.H. 2021. Diagnosis and Management of Osteoporosis During COVID-19: Systematic Review and Practical Guidance. Calcif Tissue Int 109(4): 351-62

Holick, M.F. 2005. The influence of vitamin D on bone health across the life cycle. J Nutr 135(11): 2726s-7s.

Hong, A.R., Kim, S.W. 2018. Effects of resistance exercise on bone health. Endocrinol Metab (Seoul) 33(4): 435-44.

Huang, C., Huang, L., Wang, Y., Li, X., Ren, L., Gu, X., Kang, L., Guo, L., Liu, M., Zhou, X., Luo, J., Huang, Z., Tu, S., Zhao, Y., Chen, L., Xu, D., Li, Y., Li, C., Peng, L., Li, Y., Xie, W., Cui, D., Shang, L., Fan, G., Xu, J., Wang, G., Wang, Y., Zhong, J., Wang, C., Wang, J., Zhang, D., Cao, B. 2021. 6-month consequences of COVID-19 in patients discharged from hospital: a cohort study. Lancet 397(10270): 220-32.

Huang, C., Wang, Y., Li, X., Ren, L., Zhao, J., Hu, Y., Zhang, L., Fan, G., Xu, J., Gu, X., Cheng, Z., Yu, T., Xia, J., Wei, Y., Wu, W., Xie, X., Yin, W., Li, H., Liu, M., Xiao, Y., Gao, H., Guo, L., Xie, J., Wang, G., Jiang, R., Gao, Z., Jin, Q., Wang, J., Cao, B. 2020. Clinical features of patients infected with 2019 novel coronavirus in Wuhan, China. Lancet 395(10223): 497-506.

Janssen, H.C., Samson, M.M., Verhaar, H.J. 2002. Vitamin D deficiency, muscle function, and falls in elderly people. Am J Clin Nutr 75(4): 611-5.

Johnell, O., Kanis, J. 2005. Epidemiology of osteoporotic fractures. Osteoporos Int 16(Suppl 2): S3-7.

Jones, K.S., Assar, S., Harnpanich, D., Bouillon, R., Lambrechts, D., Prentice, A., Schoenmakers, I. 2014. 25(OH)D2 half-life is shorter than $25(\mathrm{OH}) \mathrm{D} 3$ half-life and is influenced by DBP concentration and genotype. J Clin Endocrinol Metab 99(9): 3373-81.

Kanis, J.A., Harvey, N.C., Cooper, C., Johansson, H., Odén, A., McCloskey, E.V. 2016. A systematic review of intervention thresholds based on FRAX. Arch Osteoporos 11(1): 25.

Kanis, J.A., Odén, A., McCloskey, E. V., Johansson, H., Wahl, D.A., Cooper, C. 2012. A systematic review of hip fracture incidence and probability of fracture worldwide. Osteoporos Int 23(9): 2239-56.

Kilroe, S.P., Fulford, J., Jackman, S.R., Van Loon, L.J., Wall, B.T. 2019. Temporal muscle-specific disuse atrophy during one week of leg immobilization. Med Sci Sports Exerc 52(4): 944-54.

Kim, H.S., Kim, D.G. 2013. Effect of long-term resistance exercise on body composition, blood lipid factors, and vascular compliance in the hypertensive elderly men. J Exerc Rehabil 9(2): 271-7.

Landi, F., Calvani, R., Cesari, M., Tosato, M., Martone, A.M., Bernabei, R., Onder, G., Marzetti, E. 2015. Sarcopenia as the biological substrate of physical frailty. Clin Geriatr Med 31(3): 367-74.

Laskowski, E.R., Johnson, S.E., Shelerud, R.A., Lee, J.A., Rabatin, A.E., Driscoll, S.W., Moore, B. J., Wainberg, M.C., Terzic, C.M. 2020. The telemedicine musculoskeletal examination. Mayo Clin Proc 95(8): 1715-31.

Leder, B.Z., Neer, R.M., Wyland, J.J., Lee, H.W., Burnett-Bowie, S.-A.M., Finkelstein, J.S. 2009. Effects of teriparatide treatment and discontinuation in postmenopausal women and eugonadal men with osteoporosis. J Clin Endocrinol Metab 94(8): 2915-21.

Lei, L., Huang, X., Zhang, S., Yang, J., Yang, L., Xu, M. 2020. Comparison of prevalence and associated factors of anxiety and depression among people affected by versus people unaffected by quarantine during the COVID-19 epidemic 
in Southwestern China. Med Sci Monit 26: e924609.

Liao, C.D., Tsauo, J.Y., Chiu, Y.S., Ku, J.W., Huang, S.W., Liou, T.H. 2020. Effects of elastic resistance exercise after total knee replacement on muscle mass and physical function in elderly women with osteoarthritis: a randomized controlled trial. Am J Phys Med Rehabil 99(5): 381-9.

Lim, M.A., Mulyadi Ridia, K.G., Pranata, R. 2021. Epidemiological pattern of orthopaedic fracture during the COVID-19 pandemic: A systematic review and meta-analysis. J Clin Orthop Trauma 16: 16-23.

Lim, M.A., Pranata, R. 2021. Coronavirus disease 2019 (COVID-19) markedly increased mortality in patients with hip fracture - A systematic review and meta-analysis. J Clin Orthop Trauma 12(1): 187-93.

Lim, P.S., Ong, F.B., Adeeb, N., Seri, S.S., Noor-Aini, M.Y., Shamsuddin, K., Hapizah, N., Mohamed, A.L., Mokhtar, A., Wan, H.W. 2005. Bone health in urban midlife Malaysian women: risk factors and prevention. Osteoporos Int 16(12): 2069-79.

Lindsay, J.R., Lawrenson, G., English, S. 2020. A service evaluation of e-triage in the osteoporosis outpatient clinic-an effective tool to improve patient access? Arch Osteoporos 15(1): 53.

Luo, J., Quan, Z., Lin, S., Cui, L. 2018. The association between blood concentration of 25-hydroxyvitamin D and sarcopenia: a metaanalysis. Asia Pac J Clin Nutr 27(6): 1258-70.

Macaulay, T.R., Fisher, B.E., Schroeder, E.T. 2020. Potential indirect mechanisms of cognitive enhancement after long-term resistance training in older adults. Phys Ther 100(6): 907-16.

Malik-Tabassum, K., Crooks, M., Robertson, A., To, C., Maling, L., Selmon, G. 2020. Management of hip fractures during the COVID-19 pandemic at a high-volume hip fracture unit in the United Kingdom. J Orthop 20: 332-7.

Maniscalco, P., Poggiali, E., Quattrini, F., Ciatti, C., Magnacavallo, A., Vercelli, A., Domenichini, M., Vaienti, E., Pogliacomi, F., Ceccarelli, F. 2020. Proximal femur fractures in COVID-19 emergency: the experience of two Orthopedics and Traumatology Departments in the first eight weeks of the Italian epidemic. Acta Biomed 91(2): 89-96.

Marshall, J.K. 2002. The gastrointestinal tolerability and safety of oral bisphosphonates. Expert Opin Drug Saf 1(1): 71-8.

Martineau, A.R., Jolliffe, D.A., Hooper, R.L., Greenberg, L., Aloia, J.F., Bergman, P., DubnovRaz, G., Esposito, S., Ganmaa, D., Ginde, A. A., Goodall, E.C., Grant, C.C., Griffiths, C.J., Janssens, W., Laaksi, I., Manaseki-Holland, S., Mauger, D., Murdoch, D.R., Neale, R., Rees, J.R., Simpson, S., Stelmach, I., Kumar, G.T.,
Urashima, M., Camargo, C.A. 2017. Vitamin D supplementation to prevent acute respiratory tract infections: systematic review and metaanalysis of individual participant data. BMJ 356: i6583.

McCloskey, E.V., Harvey, N.C., Johansson, H., Lorentzon, M., Vandenput, L., Liu, E., Kanis, J.A. 2021. Global impact of COVID-19 on non-communicable disease management: descriptive analysis of access to FRAX fracture risk online tool for prevention of osteoporotic fractures. Osteoporos Int 32(1): 39-46.

Ministry of Health Malaysia. 2015. Clinical guidelines on management of osteoporosis. http://www. moh.gov.my/moh/resources/Penerbitan/ CPG/Rheumatology/CPG\%20Mx\%20of\%20 Osteoporosis\%20Second\%20Edition\%20 (2015).pdf [26 July 2021]

Ministry of Health Malaysia. 2021. Situasi Terkini COVID-19 di Malaysia 27 OGOS 2021. http:// https://covid-19.moh.gov.my/terkini [27 August 2021]

Mora, J.R., Iwata, M., von Andrian, U.H. 2008. Vitamin effects on the immune system: vitamins $\mathrm{A}$ and D take centre stage. Nat Rev Immunol 8(9): 685-98.

Napoli, N., Elderkin, A.L., Kiel, D.P., Khosla, S. 2020. Managing fragility fractures during the COVID-19 pandemic. Nat Rev Endocrinol 16(9): 467-8.

Nascimento, D.D.C., da Silva, C.R., Valduga, R., Saraiva, B., de Sousa Neto, I.V., Vieira, A., Funghetto, S.S., Silva, A.O., Oliveira, S.D.C., Pereira, G.B., Willardson, J.M., Prestes, J. 2018. Blood pressure response to resistance training in hypertensive and normotensive older women. Clin Interv Aging 13: 541-53.

Narla, R.R., Adler, R.A. 2021. Osteoporosis care amidst the prolonged pandemic. J Endocrinol Invest 44(7): 1353-61.

NIH Consensus Development Panel on Osteoporosis Prevention, D., and Therapy. 2001. Osteoporosis prevention, diagnosis, and therapy. JAMA 285(6): 785-795.

Ogliari, G., Lunt, E., Ong, T., Marshall, L., Sahota, O. 2020. The impact of lockdown during the COVID-19 pandemic on osteoporotic fragility fractures: an observational study. Arch Osteoporos 15(1): 1-8.

Oswald, A.J., Berg, K., Ralston, S.H., Riches, P.L. 2019. Long-term effects of teriparatide followed by antiresorptive therapy on clinical outcomes in patients with severe spinal osteoporosis. Calcif Tissue Int 105(2): 148-55.

Palcu, P., Munce, S., Jaglal, S., Allin, S., Chishtie, J., Silverstein, A., Kim, S. 2020. Understanding patient experiences and challenges to osteoporosis care delivered virtually by telemedicine: a mixed methods study. 
Osteoporos Int 31(2): 351-61.

Pereira, M., Dantas Damascena, A., Galvão Azevedo, L.M., de Almeida Oliveira, T., da Mota Santana, J. 2020. Vitamin D deficiency aggravates COVID-19: systematic review and meta-analysis. Crit Rev Food Sci Nutr: 1-9.

Perron, R.M., Lee, P. 2013. Efficacy of high-dose vitamin D supplementation in the critically ill patients. Inflamm Allergy Drug Targets 12(4): 273-81.

Pfeifer, M., Begerow, B., Minne, H.W., Suppan, K., Fahrleitner-Pammer, A., Dobnig, H. 2009. Effects of a long-term vitamin D and calcium supplementation on falls and parameters of muscle function in community-dwelling older individuals. Osteoporos Int 20(2): 315-22.

Pietrobelli, A., Pecoraro, L., Ferruzzi, A., Heo, M., Faith, M., Zoller, T., Antoniazzi, F., Piacentini, G., Fearnbach, S.N., Heymsfield, S.B. 2020. Effects of COVID-19 lockdown on lifestyle behaviors in children with obesity living in verona, italy: a longitudinal study. Obesity (Silver Spring) 28(8): 1382-5.

Popp, A.W., Senn, R., Curkovic, I., Senn, C., Buffat, H., Popp, P.F., Lippuner, K. 2017. Factors associated with acute-phase response of bisphosphonate-naïve or pretreated women with osteoporosis receiving an intravenous first dose of zoledronate or ibandronate. Osteoporos Int 28(6): 1995-2002.

Rahman, S.A., Chee, W.S., Yassin, Z., Chan, S.P. 2004. Vitamin D status among postmenopausal Malaysian women. Asia Pac J Clin Nutr 13(3): 255-60.

Remmelts, H.H., van de Garde, E.M., Meijvis, S.C., Peelen, E.L., Damoiseaux, J.G., Grutters, J.C., Biesma, D.H., Bos, W.J., Rijkers, G.T. 2012. Addition of Vitamin D Status to Prognostic Scores Improves the Prediction of Outcome in Community-Acquired Pneumonia. Clin Infect Dis 55(11): 1488-94.

Sanyaolu, A., Okorie, C., Marinkovic, A., Patidar, R., Younis, K., Desai, P., Hosein, Z., Padda, I., Mangat, J., Altaf, M. 2020. Comorbidity and its Impact on Patients with COVID-19. SN Compr Clin Med 2020: 1-8

Sapkota, H.R., Nune, A., Bateman, J., Venkatachalam, S. 2021. A pragmatic proposal for triaging DXA testing during the COVID-19 global pandemic. Osteoporos Int 32(1): 1-6.

Schwartz, A.V., Bauer, D.C., Cummings, S.R., Cauley, J.A., Ensrud, K.E., Palermo, L., Wallace, R.B., Hochberg, M.C., Feldstein, A.C., Lombardi, A. 2010. Efficacy of continued alendronate for fractures in women with and without prevalent vertebral fracture: the FLEX trial. J Bone Miner Res 25(5): 976-82.

Shafinaz, I.S., Moy, F.M. 2016. Vitamin D level and its association with adiposity among multi- ethnic adults in Kuala Lumpur, Malaysia: a cross sectional study. BMC Public Health 16: 232.

Shepstone, L., Lenaghan, E., Cooper, C., Clarke, S., Fong-Soe-Khioe, R., Fordham, R., Gittoes, N., Harvey, I., Harvey, N., Heawood, A., Holland, R., Howe, A., Kanis, J., Marshall, T., O'Neill, T., Peters, T., Redmond, N., Torgerson, D., Turner, D., McCloskey, E., Shepstone, L., Lenaghan, E., Cooper, C., Clarke, S., Fong-Soe-Khioe, R., Fordham, R., Gittoes, N., Harvey, I., Harvey, N., Heawood, A., Holland, R., Howe, A., Kanis, J., Marshall, T., O'Neill, T., Peters, T., Redmond, N., Torgerson, D., Turner, D., McCloskey, E., Crabtree, N., Duffy, H., Parle, J., Rashid, F., Stant, K., Taylor, K., Thomas, C., Knox, E., Tenneson, C., Williams, H., Adams, D., Bion, V., Blacklock, J., Dyer, T., Bratherton, S., Fidler, M., Knight, K., McGurk, C., Smith, K., Young, S., Collins, K., Cushnaghan, J., Arundel, C., Bell, K., Clark, L., Collins, S., Gardner, S., Mitchell, N. 2018. Screening in the community to reduce fractures in older women (SCOOP): a randomised controlled trial. Lancet 391(10122): 741-7.

Stephens, A., Rudd, H., Stephens, E., Ward, J. 2020. Secondary Prevention of Hip Fragility Fractures During the COVID-19 Pandemic: Service Evaluation of "MRS BAD BONES". JMIR aging 3(2): e25607.

Stewart, V., Saunders, D., Greig, C. 2014. Responsiveness of muscle size and strength to physical training in very elderly people: a systematic review. Scand J Med Sci Sports 24(1): e1-e10.

Tanaka, M.J., Oh, L.S., Martin, S.D., Berkson, E.M. 2020. Telemedicine in the Era of COVID-19: the virtual orthopaedic examination. J Bone Joint Surg Am 102(12): e57.

Tenforde, A.S., Borgstrom, H., Polich, G., Steere, H., Davis, I.S., Cotton, K., O'Donnell, M., Silver, J. K. 2020. Outpatient physical, occupational, and speech therapy synchronous telemedicine: a survey study of patient satisfaction with virtual visits during the COVID-19 Pandemic. Am J Phys Med Rehabil 99(11): 977-81.

Tricco, A.C., Thomas, S.M., Veroniki, A.A., Hamid, J.S., Cogo, E., Strifler, L., Khan, P.A., Robson, R., Sibley, K.M., MacDonald, H., Riva, J.J., Thavorn, K., Wilson, C., Holroyd-Leduc, J., Kerr, G.D., Feldman, F., Majumdar, S.R., Jaglal, S.B., Hui, W., Straus, S.E. 2017. Comparisons of interventions for preventing falls in older adults: a systematic review and meta-analysis. JAMA 318(17): 1687-99.

Tsourdi, E., Langdahl, B., Cohen-Solal, M., AubryRozier, B., Eriksen, E.F., Guañabens, N., Obermayer-Pietsch, B., Ralston, S.H., Eastell, R., Zillikens, M.C. 2017. Discontinuation of denosumab therapy for osteoporosis: a 
systematic review and position statement by ECTS. Bone 105: 11-17.

Van Schoor, N., Lips, P. 2017. Global overview of vitamin D status. Endocrinol Metab Clin North Am 46(4): 845-70.

Wang, H., Chen, W., Li, D., Yin, X., Zhang, X., Olsen, N., Zheng, S.G. 2017. Vitamin D and chronic diseases. Aging Dis 8(3): 346.

Watts, N., Chines, A., Olszynski, W., McKeever, C., McClung, M., Zhou, X., Grauer, A. 2008. Fracture risk remains reduced one year after discontinuation of risedronate. Osteoporos Int 19(3): 365-72.

World Health Organization. 2021. Coronavirus disease (COVID-19) Weekly epidemiological update and weekly operational update. http:// https://www.who.int/publications/m/item/ weekly-epidemiological-update-on-covid-19--27-july-2021 [31 July 2021]

Wu, H., Pang, Q. 2017. The effect of vitamin D and calcium supplementation on falls in older adults : A systematic review and meta-analysis. Orthopade 46(9): 729-36.

Xiong, X., Chi, J., Gao, Q. 2021. Prevalence and risk factors of thrombotic events on patients with COVID-19: a systematic review and metaanalysis. Thromb / 19(1): 32.
Yoon, J.R., Ha, G.C., Kang, S.J., Ko, K.J. 2019. Effects of 12-week resistance exercise and interval training on the skeletal muscle area, physical fitness, and mental health in old women. J Exerc Rehabil 15(6): 839-847.

Yu, E. W., Tsourdi, E., Clarke, B.L., Bauer, D.C., Drake, M.T. 2020. Osteoporosis Management in the Era of COVID-19. J Bone Miner Res 35(6): 1009-13.

Zhong, B.L., Chen, S.L., Tu, X., Conwell, Y. 2017. Loneliness and cognitive function in older adults: findings from the chinese longitudinal healthy longevity survey. J Gerontol B Psychol Sci Soc Sci 72(1): 120-8.

Zhou, F., Yu, T., Du, R., Fan, G., Liu, Y., Liu, Z., Xiang, J., Wang, Y., Song, B., Gu, X., Guan, L., Wei, Y., Li, H., Wu, X., Xu, J., Tu, S., Zhang, Y., Chen, H., Cao, B. 2020. Clinical course and risk factors for mortality of adult inpatients with COVID-19 in Wuhan, China: a retrospective cohort study. Lancet 395(10229): 1054-62.

Received: 22 Aug 2021

Accepted: 15 Oct 2021 